\title{
Powerful methods to establish chromosomal markers in Lactococcus lactis: an analysis of pyrimidine salvage pathway mutants obtained by positive selections
}

\author{
Jan Martinussen and Karin Hammer
}

Department of

Microbiology, Technical University of Denmark, Anker Engelundsvej, DK2800 Lyngby, Denmark
Author for correspondence: Jan Martinussen. Tel: +45452524 98. Fax: +4545882660 .

\begin{abstract}
Using different 5-fluoropyrimidine analogues, positive selection procedures for obtaining mutants blocked in pyrimidine and purine salvage genes of Lactococcus lactis were established. Strains lacking the following enzyme activities due to mutations in the corresponding genes were isolated: uracil phosphoribosyltransferase (upp), uridine/cytidine kinase (udk), pyrimidine nucleoside phosphorylase (pdp), cytidine/deoxycytidine deaminase (cdd), thymidine kinase (tdk) and purine nucleoside phosphorylase (pup). Based on an analysis of the mutants obtained, the pathways by which $L$. lactis metabolizes uracil and the different pyrimidine nucleosides were verified. The substrate specificities of the different enzymes were determined. It was demonstrated that a single pyrimidine nucleoside phosphorylase accounts for the phosphorolytical cleavage of uridine, deoxyuridine and thymidine, and a single purine nucleoside phosphorylase has activity towards both the ribonucleoside and deoxyribonucleoside derivatives of adenine, guanine and hypoxanthine. No phosphorylase activity towards xanthosine appeared to be present. The selection procedures developed during this work may be employed in establishing markers on the chromosome of many related lactic acid bacteria.
\end{abstract}

Keywords: Lactococcus lactis, chromosomal markers, nucleotide metabolism, pyrimidine salvage pathway mutants, positive selections

\section{INTRODUCTION}

Lactococcus lactis has been shown to grow on a defined medium without nucleosides or nucleobases added, i.e. it contains the pathways for de novo synthesis of nucleotides (Jensen \& Hammer, 1993). In contrast to the de novo pathways which, when present, seem to contain the same enzymic steps in all organisms, the salvage pathways may vary considerably in different bacteria. This provides the basis for differential usage of toxic nucleoside or nucleobase analogues to inhibit some bacteria. Furthermore, knowledge of the salvage pathways of a given bacterium

\footnotetext{
Abbreviations: AdR, deoxyadenosine; $A R$, adenosine; $C d R$, deoxycytidine; CR, cytidine; dR-1-P, deoxyribose-1-phosphate; FCdR, 5-fluorodeoxycytidine; FCR, 5-fluorocytidine; FdUMP, 5-fluoro-dUMP; FU, 5-fluorouracil; FUdR, 5-fluorodeoxyuridine; FUMP, 5-fluoro-UMP; FUR, 5-fluorouridine; $\mathrm{GdR}$, deoxyguanosine; GR, guanosine; $\mathrm{Hx}$, hypoxanthine; IdR, deoxyinosine; IR, inosine; P-1-P, pentose 1-phosphate; PRPP, 5-phosphoribosyl-1diphosphate; R-1-P, ribose 1-phosphate; UdR, deoxyuridine; UPRTase, uracil phosphoribosyltransferase; UR, uridine.
}

is very important for the experimental use of radioactive nucleosides or nucleobases for in vivo labelling of RNA and DNA.

In lactococci, part of the purine salvage pathways have been studied and the bpt gene encoding hypoxanthine guanine phosphoribosyltransferase has been cloned and sequenced (Nilsson \& Lauridsen, 1992). Recently, the nature of the pyrimidine salvage pathways of $L$. lactis have been elaborated by investigating the effect of 5fluoropyrimidines on growth, by testing the ability of different pyrimidine derivatives to facilitate growth of a pyrimidine-requiring strain, and by assaying the presence or absence of enzyme activities in cell extracts from wildtype strains (Martinussen et al., 1994). Furthermore, the uracil phosphoribosyltransferase gene $(u p p)$ has been cloned and sequenced in our laboratory (Martinussen \& Hammer, 1994).

In the work described in this report, we utilized the sensitivity of $L$. lactis to most 5-fluoropyrimidine deriva- 
tives to define conditions for positive selection of mutants in the salvage pathways since these analogues are only toxic to the bacterial cell after being converted by the corresponding salvage enzymes. The most toxic metabolite formed inside the cell has been identified as 5fluorodeoxyuridine monophosphate (FdUMP), which covalently binds to thymidylate synthase, the enzyme catalysing the formation of dTMP from dUMP (Heidelberger et al., 1983).

We describe positive selections for $u p p, u d k, t d k$ and $c d d$ mutants in wild-type $L$. lactis by modification of the procedures developed for Salmonella typhimurium by Beck and co-workers (Beck \& Ingraham, 1971; Beck et al., 1972). The selections developed for $p d p$ and $p u p$ mutants were performed in $u p p$ or $u p p t d k$ parental strains as originally proposed for Escherichia coli by Ahmad \& Pritchard (1969). Altogether, ten different conditions are described which can be used for selection of spontaneous mutants with frequencies from $3 \times 10^{-4}$ to $2 \times 10^{-7}$. The corresponding salvage genes are expected to be located on the bacterial chromosome as found for hpt (Nilsson \& Lauridsen, 1992) and $u p p$ (Martinussen \& Hammer, 1994). Thus, the selections described are useful for establishment of chromosomal markers for genetic experiments in $L$. lactis. Previously, a positive selection procedure exploiting toxic $\mathrm{L}$-alanine analogues has been described for isolating mutants in the oligopeptide transport system of $L$. lactis (Kunji et al., 1993). Also, selections for resistance to antibiotics such as rifampicin (Lautier et al., 1988) and streptomycin (Gasson, 1983), have been developed.

The enzymic analysis of the mutants obtained has extended the knowledge of the salvage pathways in $L$. lactis, particularly with respect to the number of enzymes involved. Only one pyrimidine ribonucleoside kinase $(u d k)$, one pyrimidine nucleoside phosphorylase $(p d p)$ and one purine nucleoside phosphorylase $(p u p)$ were found in this organism, and cytidine deaminase ( $c d d)$ was found to use both cytidine and deoxycytidine as substrates.

\section{METHODS}

Bacterial strains and growth procedure. The strains used in this work are all derivatives of $L$. lactis subsp. cremoris MG1363 (Gasson, 1983). This laboratory strain has been cured of plasmids and prophages. The genotypes of the strains are presented in Table 1. Cultures were grown on SAG medium consisting of $1 \%$ glucose in the MOPS-based, defined medium SA containing 7 vitamins and 19 amino acids (Jensen \& Hammer, 1993). When needed, 5-fluorouracil and 5-fluorocytosine $\left(5 \mu \mathrm{g} \mathrm{ml}^{-1}\right)$, other fluoro analogues $\left(10 \mu \mathrm{g} \mathrm{ml}^{-1}\right)$, uracil $\left(20 \mu \mathrm{g} \mathrm{ml}^{-1}\right)$ and uridine and cytidine $\left(40 \mu \mathrm{g} \mathrm{ml}^{-1}\right)$ were added to the medium. Alternatively, the cells were grown in M17 broth (Terzaghi \& Sandine, 1975) supplied with $1 \%$ glucose (GM17) or $0.5 \%$ xanthosine (XM17). For plating medium, agar was added at $15 \mathrm{~g} \mathrm{l}^{-1}$. In liquid media, the cells were grown without shaking. All incubations were at $30^{\circ} \mathrm{C}$ in the presence of oxygen.

Enzyme assays. The cells were grown overnight in SAG medium, harvested, washed and resuspended in $50 \mathrm{mM}$ Tris/ $\mathrm{HCl} \mathrm{pH} \mathrm{7•8,1} \mathrm{mM} \mathrm{EDTA} \mathrm{and} 1 \mathrm{mM}$ dithiothreitol, resulting in
Table 1. L. lactis strains used

\begin{tabular}{|c|c|c|c|}
\hline Strain & $\begin{array}{l}\text { Relevant } \\
\text { genotype }\end{array}$ & $\begin{array}{c}\text { Parental } \\
\text { strain }\end{array}$ & $\begin{array}{c}\text { Source/ } \\
\text { selection* }\end{array}$ \\
\hline MG1363 & Wild-type & & Gasson (1983) \\
\hline MB103 & $t d k-1$ & MG1363 & $\mathrm{FUdR}_{10}+\mathrm{U}_{30}$ \\
\hline MB105 & $u d k-1$ & MG1363 & $\mathrm{FUR}_{5}+\mathrm{U}_{30}$ \\
\hline MB109 & $c d d-1$ & MG1363 & $\mathrm{FCdR}_{0.5}$ \\
\hline MB112 & $u p p-1$ & MG1363 & $\begin{array}{l}\text { Martinussen \& } \\
\text { Hammer (1994) }\end{array}$ \\
\hline MB113 & $u p p-3$ & MG1363 & $\mathrm{FU}_{0 \cdot 3}$ \\
\hline MB116 & $u p p-12$ tdk-1 & MB103 & $\mathrm{FU}_{10}$ \\
\hline MB117 & $u p p-1 p d p-1$ & MB112 & $\mathrm{FU}_{10}+\mathrm{AR}_{500}$ \\
\hline MB128 & upp-1 udk-4 & MB112 & $\mathrm{FUR}_{5}+\mathrm{U}_{30}$ \\
\hline MB130 & $u p p-1 p d p-21$ & MB112 & $\mathrm{FU}_{10}+\mathrm{GdR}_{500}$ \\
\hline MB139 & $u p p-12$ tdk-1 pdp-11 & MB116 & $\mathrm{FU}_{10}+\mathrm{AR}_{500}$ \\
\hline MB140 & $u p p-12$ tdk-1 pup-1 & MB116 & $\mathrm{FU}_{10}+\mathrm{AR}_{500}$ \\
\hline
\end{tabular}

* All strains except MG1363 and MB112 are from this work and the selections used are shown. Subscripts indicate the concentrations of metabolites added to the medium in $\mu \mathrm{g} \mathrm{ml}^{-1}$.

a 100 -fold concentration of the cells. They were lysed using a French pressure cell at 20000 p.s.i. (138 MPa). Cell debris was removed by centrifugation and the supernatant was used directly as enzyme source in the assays. The uracil phosphoribosyltransferase assay was performed according to Rasmussen $e t$ al. (1986). Thymidine and uridine phosphorylases, uridine and cytidine kinases, and cytidine and deoxycytidine deaminases were assayed as described previously (Martinussen \& Hammer, 1994). Thymidine kinase was assayed as described by Martinussen \& Hammer (1994), with the modification that phosphoenolpyruvate $(8.4 \mathrm{mM})$ and pyruvate kinase $\left(20\right.$ units $\left.\mathrm{ml}^{-1}\right)$ were included. Purine nucleoside phosphorylase activity was assayed using either the thiobarbituric acid method (deoxyadenosine and deoxyguanosine) or the xanthine oxidase coupled assay (inosine, deoxyinosine and xanthosine) as described by Jensen \& Nygaard (1975). Units are defined as nanomoles substrate transformed per minute at $30^{\circ} \mathrm{C}$ and enzyme activities are expressed in units per $\mathrm{mg}$ of total protein in the crude extracts. Protein determination was performed according to the Lowry method.

Selection procedures. In all selections, six cultures of each strain were inoculated from different single colonies and grown overnight in GM17 medium. Cells were washed and resuspended in an equal volume of $0.9 \% \mathrm{NaCl}$, and $2 \times 10^{7}$ or $2 \times 10^{6}$ cells as indicated in Table 2 were spread on minimal SA plates supplied with different 5-fluoropyrimidines. The cells were not subjected to mutagenesis. The genetic background and the conditions used in the different positive selection procedures are presented in Table 2 . In each selection, at least six resistant colonies from the six independently inoculated cultures were screened on plates containing the different 5-fluoropyrimidines.

\section{RESULTS}

The use of 5-fluoropyrimidine derivatives for selection of mutants requires that the chosen component can be transported and converted to nucleotides by the cell. If the normal pathway is mutated or the uptake is impaired, 
Table 2. Positive selections used

\begin{tabular}{|c|c|c|c|c|c|c|c|}
\hline $\begin{array}{l}\text { Mutant } \\
\text { obtained }\end{array}$ & $\begin{array}{c}\text { Corresponding } \\
\text { enzyme }\end{array}$ & $\begin{array}{c}\text { Genetic } \\
\text { background }\end{array}$ & $\begin{array}{c}\text { Selection } \\
\text { procedure } † \ddagger\end{array}$ & $\begin{array}{l}\text { Frequency of } \\
\text { resistance }\end{array}$ & $\begin{array}{c}\text { Screened } \\
\text { phenotype } \ddagger \rrbracket\end{array}$ & $\begin{array}{c}\text { Frequency } \\
\text { of } \\
\text { analogue } \\
\text { sensitivity } \\
\text { (\%)\| }\end{array}$ & $\begin{array}{c}\text { Frequency } \\
\text { in } \\
\text { assay } 9\end{array}$ \\
\hline$u p p$ & UPR'Tase & $\begin{array}{l}\text { Wild-type } \\
t d k\end{array}$ & $\begin{array}{l}\mathrm{FU}_{0 \cdot 3} \\
\mathrm{FU}_{10}\end{array}$ & $\begin{array}{l}1.1 \times 10^{-5} \\
1.5 \times 10^{-7}\end{array}$ & $\begin{array}{l}\text { FU }_{1}^{\mathrm{s}} \\
\text { FUR }_{10}^{\mathrm{s}}\end{array}$ & $\begin{array}{r}81 \\
100\end{array}$ & $\begin{array}{l}2 / 15 \\
6 / 6\end{array}$ \\
\hline$u d k$ & Uridine kinase & $\begin{array}{l}\text { Wild-type } \\
u p p \\
u p p t d k\end{array}$ & $\begin{array}{l}\mathrm{FUR}_{5}+\mathrm{U}_{30}{ }^{*} \\
\mathrm{FUR}_{5}+\mathrm{U}_{30} \\
\mathrm{FU}_{10}+\mathrm{AR}_{500}\end{array}$ & $\begin{array}{l}4 \cdot 4 \times 10^{-6} \\
2 \cdot 3 \times 10^{-6} \\
4 \cdot 1 \times 10^{-6}\end{array}$ & $\begin{array}{l}\text { FUR } \\
\text { FU }_{10}^{\mathrm{s}} \\
\text { FUR }_{10}^{\mathrm{r}}\end{array}$ & $\begin{array}{l}75 \\
44 \\
31\end{array}$ & $\begin{array}{l}1 / 8 \\
7 / 7 \\
5 / 6\end{array}$ \\
\hline$t d k$ & $\begin{array}{l}\text { Thymidine } \\
\text { kinase }\end{array}$ & $\begin{array}{l}\text { Wild-type } \\
u p p \\
u p p\end{array}$ & $\begin{array}{l}\mathrm{FUdR}_{10}+\mathrm{U}_{30} \\
\mathrm{FU}_{10}+\mathrm{GdR}_{500} \\
\mathrm{FU}_{10}{ }^{*}\end{array}$ & $\begin{array}{l}2.3 \times 10^{-7} \\
2 \cdot 5 \times 10^{-6} \\
3 \cdot 2 \times 10^{-4}\end{array}$ & $\begin{array}{l}\text { FUdR }_{10}^{\mathbf{s}} \\
\text { FUdR }_{10}^{r} \\
\text { FUdR }\end{array}$ & $\begin{array}{r}100 \\
33 \\
10\end{array}$ & $\begin{array}{l}5 / 6 \\
4 / 4 \\
4 / 4\end{array}$ \\
\hline$p d p$ & $\begin{array}{l}\text { Pyrimidine } \\
\text { nucleoside } \\
\text { phosphorylase }\end{array}$ & $\begin{array}{l}u p p \\
u p p \\
u p p \\
u p p t d k\end{array}$ & $\begin{array}{l}\mathrm{FU}_{10}+\mathrm{AR}_{500} \\
\mathrm{FU}_{10}+\mathrm{GdR}_{500} \\
\mathrm{FU}_{10} * \\
\mathrm{FU}_{10}+\mathrm{AR}_{500}\end{array}$ & $\begin{array}{l}4 \cdot 1 \times 10^{-6} \\
2.5 \times 10^{-6} \\
3 \cdot 2 \times 10^{-4} \\
1.5 \times 10^{-5}\end{array}$ & $\begin{array}{l}\text { FUR }_{10}^{s} \\
\text { FUdR }_{10}^{s} \\
\text { FUdR }_{10}^{s} \\
\text { FUR }_{10}^{s}\end{array}$ & $\begin{array}{l}94 \\
61 \\
18 \\
58\end{array}$ & $\begin{array}{l}6 / 6 \\
6 / 6 \\
7 / 7 \\
6 / 9\end{array}$ \\
\hline$c d d$ & $\begin{array}{l}\text { Cytidine } \\
\text { deaminase }\end{array}$ & Wild-type & $\mathrm{FCdR}_{0.5} *$ & $3.8 \times 10^{-6}$ & FUdR & 92 & $6 / 6$ \\
\hline pup & $\begin{array}{l}\text { Purine } \\
\text { nucleoside } \\
\text { phosphorylase }\end{array}$ & $\begin{array}{l}u p p t d k \\
u p p t d k\end{array}$ & $\begin{array}{l}\mathrm{FU}_{10}+\mathrm{AR}_{500} \\
\mathrm{FU}_{10}+\mathrm{IR}_{500}\end{array}$ & $\begin{array}{l}1.5 \times 10^{-5} \\
2.2 \times 10^{-5}\end{array}$ & $\begin{array}{l}\text { FUR }_{10}^{\mathrm{s}} \\
\text { FUR }_{10}^{\mathrm{s}}\end{array}$ & $\begin{array}{l}58 \\
53\end{array}$ & $\begin{array}{l}3 / 9 \\
2 / 11\end{array}$ \\
\hline
\end{tabular}

†The number of cells plated was $2 \times 10^{7}$ or, where indicated by an asterisk, $2 \times 10^{6}$.

$\ddagger$ Subscripts indicate the concentrations of the metabolites added to the medium in $\mu \mathrm{g} \mathrm{ml}^{-1}$.

$\S s$, sensitive; r, resistant.

$\|$ Frequency of mutants with the expected 5-fluoropyrimidine-resistant phenotypes as judged by screening relative to the total number of mutants.

I Number of mutants determined by enzyme assay among the 5-fluoropyrimidine resistant cells with the expected sensitivity pattern.

the cell becomes resistant to the 5-fluoropyrimidine derivative, provided that no alternative pathway exists.

\section{Selection of upp mutants}

The main pathway of uracil incorporation is the reaction of uracil with phosphoribosyl pyrophosphate (PRPP) to form UMP. This reaction is catalysed by uracil phosphoribosyltransferase (UPRTase) encoded by the $u p p$ gene. The toxic analogue 5-fluorouracil (FU) has been used to isolate $u p p$ mutants in other bacteria (Neuhard, 1983). It was recently shown that FU is toxic to L. lactis (Martinussen et al., 1994), indicating that uracil is being metabolized. By reverse genetics, a $u p p$ strain was constructed, and surprisingly it was only resistant to very low concentrations of FU (below $0.3 \mu \mathrm{g} \mathrm{ml}^{-1}$; Martinussen \& Hammer, 1994). In order to investigate whether it was possible to isolate $u p p$ mutants directly, wild-type cells were spread on plates supplied with $0.3 \mu \mathrm{g} \mathrm{FU} \mathrm{ml}{ }^{-1}$. Resistant clones were screened for sensitivity to higher concentrations of FU, and for loss of uracil phosphoribosyltransferase (UPR Tase) activity. As shown in Table
2 , although $u p p$ mutants were obtained, the majority of clones selected on $0.3 \mu \mathrm{g} \mathrm{FU} \mathrm{m}{ }^{-1}$ did not lose their UPR Tase activity, suggesting that mutations in other loci can confer resistance to FU at low concentrations. Resistant mutants were also obtained when FU concentrations of $1,2,5,10$ and $25 \mu \mathrm{g} \mathrm{ml}^{-1}$ were used for the selection, but none of these had lost their UPRTase activity. The nature of mutants resistant to high FU concentrations was not determined. The frequency of FUresistant cells decreased with increasing FU concentration (Martinussen \& Hammer, 1994). As described below, $t d k$ mutants were readily obtained. In order to isolate $u p p$ mutants in this strain, $t d k$ cells were spread on plates containing $10 \mu \mathrm{g} \mathrm{FU} \mathrm{ml}^{-1}$. Six independently isolated resistant colonies had the same 5-fluoropyrimidine sensitivity pattern, and all had lost UPR Tase activity (Table 2).

\section{Selection of tdk mutants}

In order to isolate mutants in the $t d k$ gene encoding thymidine kinase, wild-type cells were spread on minimal medium containing FUdR (5-fluorodeoxyuridine) 


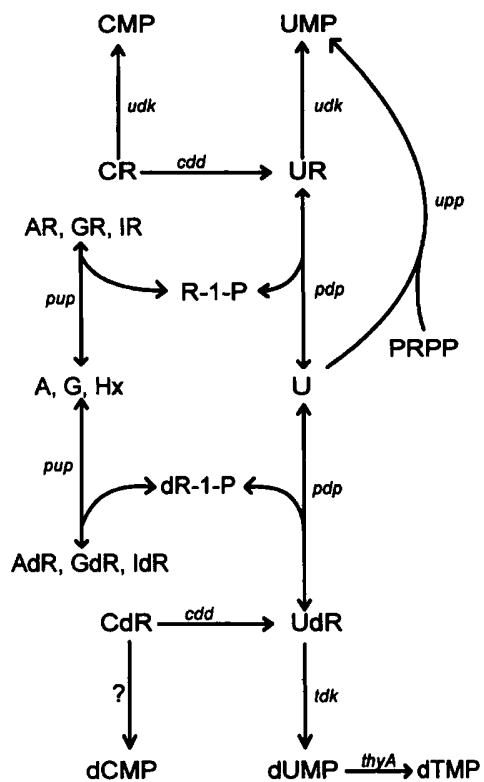

Fig. 1. Pyrimidine salvage pathways and purine nucleoside phosphorolysis reactions in L. lactis. $u d k$, uridine kinase; cdd, cytidine deaminase; upp, uracil phosphoribosyltransferase; pup, purine nucleoside phosphorylase; $p d p$, pyrimidine nucleoside phosphorylase; tdk, thymidine kinase; thyA, thymidylate synthase.

$\left(10 \mu \mathrm{g} \mathrm{ml}^{-1}\right)$ and uracil $\left(30 \mu \mathrm{g} \mathrm{ml}^{-1}\right)$. Uracil was included in order to counteract the toxic FU formed by the bacteria. As indicated in Fig. 1, FUdR can either be phosphorylated to FdUMP or may be phosphorolytically cleaved by thymidine phosphorylase resulting in the formation of deoxyribose-1-phosphate (dR-1-P) and FU.
The FU moiety may then subsequently be phosphoribosylated by the $u p p$ gene product to give FUMP (5fluoro-UMP). The presence of excess uracil was expected to inhibit the formation of FUMP, thus suppressing the toxic effect of FU. The procedure was successful: five of six resistant mutants obtained lacked thymidine kinase activity.

\section{Selection of udk mutants}

Using the same rationale as used for selection of $t d k$ mutants in a wild-type background, cells were plated on FUR (5-fluorouridine) $\left(5 \mu \mathrm{g} \mathrm{ml}^{-1}\right)$ and uracil $\left(30 \mu \mathrm{g} \mathrm{ml}^{-1}\right)$ in order to obtain mutants lacking uridine kinase activity (udk). As shown in Table 2, among eight independently isolated strains, only a single mutant in the $u d k$ gene was obtained. Using the same selection in MB112 (upp), udk mutants were readily obtained: all mutants assayed were shown to have lost uridine kinase activity. The presence of cytidine kinase activity in $L$. lactis has previously been demonstrated (Martinussen et al., 1994). No such activity could be detected in any of the udk mutants, indicating that uridine and cytidine are phosphorylated to UMP and CMP by the same enzyme (Table 3 ).

\section{Selection of $c d d$ mutants}

5-Fluorodeoxycytidine (FCdR) is deaminated to FUdR by a deaminase encoded by the $c d d$ gene. In order to obtain cdd mutants, wild-type cells were plated in the presence of FCdR at concentrations of $0.3,0.5$ and $1 \mu \mathrm{g} \mathrm{ml}^{-1}$. The frequency of resistant mutants decreased with increasing FCdR concentration, and from 0.5 to $1 \mu \mathrm{g} \mathrm{FCdR} \mathrm{ml}{ }^{-1}$ the frequency dropped by a factor of approximately ten.

Table 3. Enzymic analysis of mutants and substrate specifity of the individual enzymes

\begin{tabular}{|c|c|c|c|c|c|}
\hline \multirow{2}{*}{$\begin{array}{l}\text { Mutant } \\
\text { strain }\end{array}$} & \multirow[t]{2}{*}{ Gene } & \multirow[t]{2}{*}{ Encoded enzyme } & \multirow[t]{2}{*}{ Substrate } & \multicolumn{2}{|c|}{ Specific activity* } \\
\hline & & & & Wild-type & Mutant \\
\hline MB112 & $u p p$ & Uracil phosphoribosyltransferase & Uracil & $6 \cdot 0$ & $<0.1$ \\
\hline MB105 & udk & Uridine kinase & $\begin{array}{l}\text { Uridine } \\
\text { Cytidine }\end{array}$ & $\begin{array}{l}4 \cdot 2 \\
8 \cdot 6\end{array}$ & $\begin{array}{l}<1.2 \\
<1.3\end{array}$ \\
\hline MB103 & $t d k$ & Thymidine kinase & Thymidine & $0 \cdot 5$ & $<0.1$ \\
\hline MB139 & $p d p$ & Uridine phosphorylase & $\begin{array}{l}\text { Uridine } \\
\text { Thymidine }\end{array}$ & $\begin{array}{l}51 \\
40\end{array}$ & $\begin{array}{l}<1 \\
<1\end{array}$ \\
\hline MB130 & $p d p$ & $\begin{array}{l}\text { Thymidine } \\
\text { phosphorylase }\end{array}$ & $\begin{array}{l}\text { Uridine } \\
\text { Thymidine }\end{array}$ & $\begin{array}{l}51 \\
40\end{array}$ & $\begin{array}{l}<1 \\
<1\end{array}$ \\
\hline MB109 & $c d d$ & Cytidine deaminase & $\begin{array}{l}\text { Cytidine } \\
\text { Deoxycytidine }\end{array}$ & $\begin{array}{l}17 \\
12\end{array}$ & $\begin{array}{l}<1 \\
<1\end{array}$ \\
\hline MB140 & pup & $\begin{array}{l}\text { Purine nucleoside } \\
\text { phosphorylase }\end{array}$ & $\begin{array}{l}\text { Deoxyadenosine } \\
\text { Deoxyguanosine } \\
\text { Inosine } \\
\text { Deoxyinosine }\end{array}$ & $\begin{array}{l}76 \\
35 \\
80 \\
97\end{array}$ & $\begin{array}{l}<9 \\
<1 \\
<0 \cdot 1 \\
<0 \cdot 1\end{array}$ \\
\hline
\end{tabular}

${ }^{*}$ Specific activity is given in units (mg protein) ${ }^{-1}$ at $30^{\circ} \mathrm{C}$ in crude extract. 
Table 4. 5-Fluoropyrimidine sensitivity patterns of the isolated mutants

Strains were grown on SAG agar for $24 \mathrm{~h}$ with 5 -fluoropyrimidines added as shown.

\begin{tabular}{|c|c|c|c|c|c|c|c|c|c|c|c|}
\hline \multirow[t]{2}{*}{ Strain } & \multirow[t]{2}{*}{ Genotype } & \multicolumn{10}{|c|}{ 5-Fluoropyrimidine added* } \\
\hline & & $\mathrm{FU}_{0.3}$ & $\mathbf{F U}_{5}$ & $\mathbf{F U R}+\mathbf{U}$ & FUR & $\mathbf{F U d R}+\mathbf{U}$ & FUdR & $\mathbf{F U}+\mathbf{A R}$ & $\mathbf{F U}+\mathbf{G d R}$ & FCR & $\mathbf{F C d R}_{0.5}$ \\
\hline MG1363 & Wild-type & - & - & - & - & - & - & - & - & - & - \\
\hline MB112 & $u p p$ & + & - & - & - & - & - & - & - & - & - \\
\hline MB105 & $u d k$ & - & - & + & - & - & - & - & - & - & - \\
\hline MB128 & $u p p$ udk & + & - & + & + & - & - & - & - & + & - \\
\hline MB103 & $t d k$ & - & - & - & - & + & - & - & - & - & - \\
\hline MB116 & $t d k u p p$ & + & + & - & - & + & + & - & + & - & + \\
\hline MB139 & $t d k$ upp pdp & + & + & - & - & + & + & + & + & - & + \\
\hline MB140 & tdk $u p p p$ pup & + & + & - & - & + & + & + & + & - & + \\
\hline MB117 & $u p p p d p$ & + & + & - & - & - & - & + & + & - & - \\
\hline MB109 & $c d d$ & - & - & - & - & - & - & - & - & - & + \\
\hline
\end{tabular}

*5-Fluoropyrimidine derivatives were added at $10 \mu \mathrm{g} \mathrm{ml}^{-1}$, except where indicated by subscripts (in $\mu \mathrm{g} \mathrm{ml}^{-1}$ ). Uracil was added at $30 \mu \mathrm{g} \mathrm{m} l^{-1}$, and $A R$ and $G d R$ at $0.5 \mathrm{mg} \mathrm{m}^{-1}$.

The different FCdR-resistant mutants were screened for sensitivity for FUdR, since a $c d d$ mutant can be expected to be sensitive to this analogue (Fig. 1). Independently isolated, FUdR-sensitive mutants from each selection were assayed for deoxycytidine deaminase activity, and only among strains selected on $0.5 \mu \mathrm{g} \mathrm{FCdR} \mathrm{ml}{ }^{-1}$ were mutants found which had lost this enzyme activity (Table 2). These mutants were shown to be sensitive to FCdR concentrations of $1 \mu \mathrm{g} \mathrm{ml}^{-1}$ and above, suggesting the existence of an alternative pathway for the metabolism of deoxycytidine. The $c d d$ mutants isolated had lost both cytidine and deoxycytidine deaminase activity, indicating that both reactions are catalysed by the same enzyme (Table 3).

\section{Selection of pdp mutants}

Lactococci contain gene(s) encoding enzyme activities responsible for the phosphorolytic cleavage of uridine, deoxyuridine and thymidine (Martinussen et al., 1994). Positive selection procedures for obtaining mutants in these enzymes cannot be established in the wild-type background, but require a primary mutation, often a $u p p$ background (Neuhard, 1983). The normal pathway of uracil incorporation involves a phosphoribosylation to UMP catalysed by the upp gene product. If this pathway is blocked, the cells are resistant to FU. Certain conditions may allow FU to follow alternative pathways involving a reaction between FU and pentose-1-phosphate (P-1-P) catalysed by a pyrimidine nucleoside phosphorylase, resulting in the formation of the corresponding 5fluoropyrimidine nucleoside that subsequently will lead to death of the cell (Fig. 1). A prerequisite for this reaction is the presence of a sufficient concentration of P-1-P inside the cell. The concentration of either ribose 1-phosphate (R-1-P) or dR-1-P can be increased by the addition of purine ribonucleosides or purine deoxyribonucleosides to the growth medium. Purine nucleosides are phosphoro- lytically cleaved by a purine nucleoside phosphorylase inside the cell, resulting in the formation of the corresponding P-1-P and purine base. Therefore, it is reasonable to believe that in the upp strain, mutants in the alternative uracil pathway may be obtained by plating on FU in the presence of a purine nucleoside. As shown below, FU-resistant lactococcal strains are sensitized by addition of purine nucleosides. Alternatively, mutants may be obtained by plating on high concentrations of FU, since the $u p p$ strain is sensitive to FU concentrations above $0.3 \mu \mathrm{g} \mathrm{ml}^{-1}$, whereas a $u p p t d k$ strain is resistant, indicating that $\mathrm{dR}-1-\mathrm{P}$ is present to some extent in the cell, even in the absence of exogenous deoxyribonucleosides.

The upp strain MB112 was suitable for the isolation of a mutant unable to cleave thymidine, either by using FU in high concentration, or using $\mathrm{FU}$ in the presence of deoxyguanosine (Table 2). The presence of deoxyguanosine increases the toxicity of $\mathrm{FU}$ in the $u p p$ background, thus reducing background growth, making the selection more efficient. As expected, two classes of mutants were obtained, namely pyrimidine nucleoside phosphorylase mutants and strains lacking thymidine kinase activity. The two mutants can easily be distinguished by phenotype screening, since only the $u p p t d k$ mutants are resistant to FUdR (Table 4). The thymidine phosphorylase mutants obtained in these selections were shown to have lost both thymidine and uridine phosphorylase activities, suggesting that both enzyme activities are properties of the same polypeptide.

Strain MB116 (upp tdk) is resistant to FU in high concentrations, but becomes sensitive to $F U$ in the presence of adenosine as R-1-P donor. Thus, mutants lacking uridine phosphorylase activity were selected in strain MB116 ( $u p p t d k$ ) on plates containing FU in the presence of adenosine. Mutations in at least three different genes will result in resistance. In addition to uridinephosphorylase-deficient strains, mutants affected in uri- 
dine kinase (udk) and adenosine phosphorylase were isolated (Table 2). udk mutants are characterized by their resistance towards FUR, whereas uridine and adenosine phosphorylase mutants have the same 5-fluoropyrimidine sensitivity pattern. By screening the enzyme activities, the identity of the FUR-sensitive mutants was established, showing that mutants in both nucleoside phosphorylases were obtained (Table 2). Furthermore, both the uridine and thymidine phosphorylase activities were shown to be absent in the strains exhibiting uridine phosphorylase deficiency, as would be expected if both activities were properties of the same enzyme (see above). These results demonstrate that $L$. lactis has a general pyrimidine nucleoside phosphorylase. The corresponding gene is designated $p d p$.

In other bacteria, mutants lacking uridine phosphorylase activity have been obtained in a upp background by selection on FU in the presence of adenosine, which serves as a R-1-P donor (Neuhard, 1983). Since the $u p p$ mutation in MB112 only confers resistance to $F U$ at a very low concentration, mutations in both the $\mathrm{U} \rightarrow \mathrm{UR} \rightarrow$ $\mathrm{UMP}$ and $\mathrm{U} \rightarrow \mathrm{UdR} \rightarrow \mathrm{dUMP}$ pathways are required if plated on high FU in the presence of adenosine (Fig. 1). This demands either double mutations, or if one enzyme is shared by both pathways, a single mutation in the corresponding gene. As indicated above, the lactococcal pyrimidine nucleoside phosphorylase is responsible for the phosphorolysis of both UR and UdR. Therefore, mutants in MB112 ( $u p p$ ) selected for resistance to FU in the presence of adenosine are most likely $p d p$ mutants. Indeed, virtually all resistant mutants were shown to have lost both uridine and thymidine phosphorylase activity (Table 2).

\section{Selection of pup mutants}

Purine nucleoside phosphorylase catalyses the phosphorolytic cleavage of a purine nucleoside into a purine base and P-1-P. A general purine nucleoside phosphorylase using adenosine, inosine, guanosine and the corresponding deoxyribosyl derivatives has been described for $E$. coli (Jensen \& Nygaard, 1975), whereas in Bacillus subtilis two different enzymes (adenosine phosphorylase and inosineguanosine phosphorylase) are required for the same reactions (Jensen, 1978). As described above, mutant lactococci unable to cleave adenosine were readily isolated. The same result was obtained using inosine (Table 2). No purine nucleoside phosphorylase activity towards deoxyadenosine, deoxyguanosine, inosine or deoxyinosine as substrate could be measured in crude extracts from the different mutants isolated (Table 3). This demonstrates that only one purine nucleoside phosphorylase responsible for the cleavage of adenosine, guanosine, inosine and the corresponding deoxyribosyl derivatives is present in L. lactis when grown in rich glucose medium (GM17). An additional purine nucleoside phosphorylase activity responsible for the cleavage of xanthosine can be detected in E. coli only when grown in the presence of this substrate (Hammer-Jespersen et al., 1980). Therefore, an extract from lactococcal cells grown on rich medium supplied with xanthosine instead of glucose (XM17) was assayed for the presence of xanthosine phosphorylase activity. No activity could be measured (data not shown), suggesting that such an enzyme is absent in L. lactis.

\section{DISCUSSION}

\section{Mutant selections}

FU and the 5-fluoropyrimidine nucleosides FUR, FUdR and FCdR were used for the selections. When designing the selective conditions, it is important to consider the concentrations of the toxic analogues in relation to the number of cells plated. For the experiments given in Table 2, this is particularly important for the selections using FCdR and FU in wild-type strains. Selection for resistance to $\mathrm{FU}$ is the classical selection to obtain mutants in the upp gene. Previous work has shown that $u p p$ mutants in $L$. lactis are sensitive to concentrations above $0.3 \mu \mathrm{g} \mathrm{ml}^{-1}$. Even when this concentration of FU is used for the selection, only 2 of 15 mutants isolated have lost the corresponding enzyme activity, thus being $u p p$. The nature of the other mutants is unknown, but strains impaired in uracil uptake or overproducers of uracil may also be resistant to FU. In $B$. subtilis, a uracil overproducing strain $(p y r R)$ is viable in the presence of $1 \mu \mathrm{g}$ $\mathrm{FU} \mathrm{ml} \mathrm{m}^{-1}$, whereas $u p p$ mutations result in resistance up to $3 \mu \mathrm{g} \mathrm{ml}^{-1}$ (Martinussen et al., 1995).

Another important consideration when using 5-fluoropyrimidine nucleosides is that FU is formed by phosphorolytic cleavage by cells harbouring pyrimidine nucleoside phosphorylase ( $p d p$ ) activity (Fig. 1), and that FU may be excreted by the layer of wild-type cells on the selective medium. In the case of FUR and FUdR, concentrations of 5 and $10 \mu \mathrm{g} \mathrm{ml}^{-1}$ were used for the selections. Therefore substantial amounts of FU would be present. Since FU is toxic to L. lactis in amounts lower than $0.3 \mu \mathrm{g} \mathrm{ml}^{-1}$, a surplus of uracil $\left(30 \mu \mathrm{g} \mathrm{ml}^{-1}\right)$ was included in the selections for $u d k$ and $t d k$ mutants in a wild-type strain. The presence of this amount of uracil does obviate the effect of any FU formed as seen from the sensitivity of the isolated mutants to FUR and FUdR when uracil is omitted (Table 4).

A third principle was also used: the addition of a purine nucleoside together with FU results in a sensitive phenotype in a $u p p$ or a $u p p t d k$ strain. Formation of internal $\mathrm{P}-1-\mathrm{P}$ by the action of purine nucleoside phosphorylase facilitates the synthesis of FUR and FUdR by the reverse action of pyrimidine nucleoside phosphorylase $(p d p)$ (Fig. 1). The upp mutant of $L$. lactis, in contrast to that of $E$. coli, contains adequate internal dR-1-P to synthesize FUdR when the FU concentration is raised above $0.3 \mu \mathrm{g} \mathrm{ml}^{-1}$ (Martinussen \& Hammer, 1994). The addition of deoxyguanosine reduces background growth, thus facilitating the selection of $p d p$ or $t d k$ mutants (Table 2).

\section{Salvage pathways}

This paper describes the conditions for positive selection of mutations in six different genes encoding enzymes 
involved in the nucleoside salvage pathways in L. lactis. Based on analogy with the corresponding genes in E. coli and/or B. subtilis we have designated the genes $u p p$, udk, $t d k, p d p$, cdd and $p u p$. From the enzyme analysis of the corresponding mutants (Table 3 ) we conclude that the genes encode uracil phosphoribosyltransferase $(u p p)$, uridine-cytidine kinase (udk), thymidine kinase $(t d k)$, thymidine-uridine phosphorylase $(p d p)$, cytidine-deoxycytidine deaminase $(c d d)$, and deoxyadenosine-deoxyguanosineinosine phosphorylase ( $p u p)$. The substrate specificity of the enzymes was defined by the mutant phenotypes. Cytidine deaminase was found to use both cytidine and deoxycytidine as substrate, as found for other organisms (Neuhard, 1983). A single pyrimidine ribonucleoside kinase using both cytidine and uridine as substrate is found in L. lactis, as in E. coli (Valentin-Hansen, 1978) and B. subtilis (Orengo \& Kobayashi, 1978). Only one pyrimidine phosphorylase enzyme with activity towards both thymidine and uridine was found in L. lactis. It has been shown for $B$. subtilis that both thymidine and uridine phosphorylase activity resides within one protein encoded by $p d p$ (Rumyantseva et al., 1979). Consequently, the corresponding gene was named $p d p$. In $E$. coli, the two activities are mediated by separate enzymes: thymidine phosphorylase is encoded by $\operatorname{deo} A$ (Schwartz, 1978), whereas uridine phosphorylase is encoded by $u d p$ (Leer $e t$ al., 1977). Just as for the deoD gene product in E. coli (Jensen \& Nygaard, 1975), a single purine phosphorylase enzyme with activity towards adenine, guanine and hypoxanthine nucleosides was found in $L$. lactis. In $B$. subtilis, two purine nucleoside phosphorylases are found: adenosine phosphorylase specific for adenine-containing nucleosides, and inosine/guanosine phosphorylase (Jensen, 1978). In all organisms where purine nucleoside phosphorylases occur, the enzyme does not discriminate between ribose or deoxyribose in the substrate nucleoside (Parks \& Agarwal, 1972). This was also found for the enzyme encoded by pup in L. lactis.

The established salvage pathways for nucleosides and nucleobases in L. lactis are given in Fig. 1. They are different from those in $B$. subtilis with respect to $p u p A$ and $p u p I$, and from those in E. coli with respect to $\operatorname{deo} A$ and $u d p$. As previously described, $L$. lactis, like $B$. subtilis, does not contain a cod gene encoding cytosine deaminase (Martinussen et al., 1994). In contrast, E. coli does have the capacity to utilize this substrate (Neuhard, 1983).

The sensitivity of the $c d d$ mutants of $L$. lactis for FCdR concentrations above $0.5 \mu \mathrm{g} \mathrm{ml}^{-1}$ indicates that $L$. lactis, as $B$. subtilis but in contrast to $E$. coli, may contain a deoxycytidine kinase. Although no deoxycytidine kinase activity could be measured, such an activity may be present, accounting for the toxic effect of FCdR in high concentration despite the presence of a $c d d$ mutation. This was further indicated by testing the sensitivity of the $u p p$ tdk mutants to FCdR. FCdR is deaminated by cytidine deaminase to create FUdR, and strain MB116 (upptdk) is

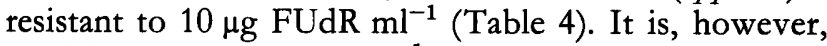

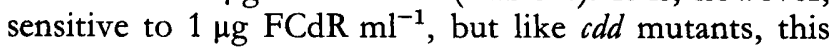
strain is resistant to $0.5 \mu \mathrm{g} \mathrm{FCdR} \mathrm{ml}{ }^{-1}$. Further experi- ments are required to determine unequivocally the nature of the sensitivity of $c d d$ mutants to FCdR.

\section{REFERENCES}

Ahmad, S. I. \& Pritchard, R. H. (1969). A map of four genes specifying enzymes involved in catabolism of nucleosides and deoxynucleosides in Eschericbia coli. Mol \& Gen Genet 104, 351-359.

Beck, C. F. \& Ingraham, J. L. (1971). Location on the chromosome of Salmonella typhimurium of genes governing pyrimidine metabolism. Mol \& Gen Genet 111, 303-316.

Beck, C. F., Ingraham, J. L. \& Neuhard, J. (1972). Location on the chromosome of Salmonella typhimurium of genes governing pyrimidine metabolism. II. Uridine kinase, cytosine deaminase, and thymidine kinase. Mol \& Gen Genet 115, 208-215.

Gasson, M. J. (1983). Plasmid complements of Streptococcus lactis NCDO 712 and other lactic streptococci after protoplast induced curing. J Bacteriol 154, 1-9.

Hammer-Jespersen, K., Buxton, R. S. \& Hansen, T. D. (1980). A second purine nucleoside phosphorylase in Escherichia coli $\mathrm{K}-12$. Mol \& Gen Genet 179, 341-348.

Heidelberger, C., Danenberg, P. V. \& Moran, R. G. (1983). Fluorinated pyrimidines and their nucleosides. In Advances in Enzymology and Related Areas in Molecular Biology, pp. 57-119. Edited by A. Meister. New York: John Wiley.

Jensen, K. F. (1978). Two purine nucleoside phosphorylases in Bacillus subtilis. Purification and some properties of the adenosinespecific phosphorylase. Biochim Biophys Acta 525, 346-356.

Jensen, K. F. \& Nygaard, P. (1975). Purine nucleoside phosphorylase from Escherichia coli and Salmonella typhimurium. Eur $J$ Biochem 51, 253-265.

Jensen, P. R. \& Hammer, K. (1993). Minimal requirements for exponential growth of Lactococcus lactis. Appl Environ Microbiol 59, 4363-4366.

Kunji, E. R., Smid, E. J., Plapp, R., Poolman, B. \& Konings, W. N. (1993). Di-tripeptides and oligopeptides are taken up via distinct transport mechanisms in Lactococcus lactis. J Bacteriol 175, 2052 2059.

Lautier, M., Gillot, B., Auffray, Y., Castillo-Sanches, X. \& Boutibonnes, P. (1988). Mutagenesis in Streptococcus lactis exposed to UV irradiation and alkylating agents. Mutagenesis 3, 245-247.

Leer, J. C., Hammer-Jespersen, K. \& Schwartz, M. (1977). Uridine phosphorylase from Escherichia coli. Physical and chemical characterization. Eur J Biochem 77, 217-224.

Martinussen, J. \& Hammer, K. (1994). Cloning and sequencing of $u p p$; a gene encoding uracil phosphoribosyltransferase from Lactococcus lactis. J Bacteriol 176, 6457-6463.

Martinussen, J., Andersen, P. S. \& Hammer, K. (1994). Nucleotide metabolism in Lactococcus lactis: salvage pathways of exogenous pyrimidines. J Bacteriol 176, 1514-1516.

Martinussen, J., Glasér, P., Andersen P. S. \& Saxild, H. H. (1995). Two genes encoding uracil phosphoribosyltransferase present in Bacillus subtilis. J Bacteriol 177, 271-274.

Neuhard, J. (1983). Utilization of preformed pyrimidine bases and nucleosides. In Metabolism of Nucleotides, Nucleosides and Nucleobases in Microorganisms, pp. 95-148. Edited by A. Munch-Petersen. London: Academic Press.

Nilsson, D. \& Lauridsen, A. A. (1992). Isolation of purine auxotrophic mutants of Lactococcus lactis and characterization of the gene bpt encoding hypoxanthine guanine phosphoribosyltransferase. Mol \& Gen Genet 235, 359-364.

Orengo, A. \& Kobayashi, S.-H. (1978). Uridine-cytidine kinase 
from Novikoff ascites rat tumor and Bacillus stearothermophilus. Methods Enqymol 51, 299-305.

Parks, R. E., Jr \& Agarwal, R. P. (1972). Purine nucleoside phosphorylase. In The Enzymes, vol. VII, 3rd edn., pp. 483-514. Edited by P. D. Boyer. New York: Academic Press.

Rasmussen, U. B., Mygind, B. \& Nygaard, P. (1986). Purification and some properties of uracil phosphoribosyltransferase from Escherichia coli K-12. Biochim Biopbys Acta 881, 268-275.

Rumyantseva, E. V., Sukhodelets, V. V. \& Smirnov, Y. V. (1979). Isolation and characterization of mutants for genes of nucleoside catabolism in Bacillus subtilis. Genetica 15, 594-604.
Schwartz, M. (1978). Thymidine phosphorylase from Escherichia coli. Methods Enzymol 51, 442-445.

Terzaghi, B. E. \& Sandine, W. E. (1975). Improved medium for lactic streptococci and their bacteriophages. Appl Environ Microbiol 29, 807-813.

Valentin-Hansen, P. (1978). Uridine-cytidine kinase from Escherichia coli. Methods Enzymol 51, 308-314.

Received 21 February 1995; revised 14 April 1995; accepted 27 April 1995. 